\title{
İSTANBUL MÜZESİNDEKİ MARİ ESERLERİ
}

\author{
Füruzan KINAL
}

Bugünkü Irak-Suriye siyasi hudutlarının Fırat nehriyle kesiştiği yerde Tel Hariri denilen köyün yanındaki büyük harabe tepesinde M.Ö. II. Binyıl başlarında büyük ve mamur bir şehir vardı. Bu harabelerden çıan satıh buluntuları üzerine, Fransız Arkeoloji cemiyeti 1933 senesinde burada kazı yapmağa karar vermiş ve ilk kazı mevsiminde bulunan saray arşivinin vesikaları ile, burasının III. Ur ve I. Babil sülaleleri vesikalarında adı geçen Mari şehri olduğu anlaşılmıştı.

Fakat, İstanbul Arkeoloji Müzesi Eski Şark bölümünde korunmakta olan Mari eserleri Mari kazılarında değil, 1899-1917 seneleri arasında ünlü Alman müsteşriki Robert Koldewey'in eski Babil şehri harabelerinde yaptığı kazılarda bulunmuştur. Ozamanlar Irak Osmanlı İmparatorluğuna tâbi olduğundan, birkaç parça eser de bizim müzemize verilmişti. Bu eserler iki başsız heykel ile bir kabartmadan ibarettir.

Bunlardan 7813 numaralı başsız heykelin üzerinde iki kitabe vardır. Heykelin kemeri hizasındaki kartuşta:

“Tura-Dagan, Mari memleketinin şakkanakku'su (ve) oğlu Puzurİștar hayatları için (bunu) adadılar" yazılıdır. Etek ucundaki kartuşta ise:

“Tura-Dagan, Mari memleketinin şakkanakku'su (ve) oğlu tanrıya, Beyine (bunu) canları için adadılar. Kaidesini bu ikisinin diktiği bu kitabeyi kim değiştirirse, Nini, Dagan, Enki ve Memleketin Beyi onun zürriyetini kurutsun" denilmektedir ${ }^{1}$. Böylece Mari valisi Tura-Dagan ile oğlu Puzur-İştar'ın bu heykeli mabede vakfettiklerini öğreniyoruz, fakat iki kitabede de baba-oğul birlikte zikredildiği için, heykelin hangisine ait olduğu tesbit edilememektedir. Fakat iyi bir tesadüf ile Babil kazılarında burada adı geçen oğul $\mathrm{Pu}$ -

\footnotetext{
1 Esat Nasuhî, AfO III (1926) s. 109-114.
} 
zur-İștar'ın heykeli de bulunduğundan, 7813 numaralı heykelin baba Tura-Dagan'a ait olduğu zannedilmektedir.

Gerçekten İstanbul arkeoloji müzesinde 7814 numarada kayıtlı bu ikinci heykelin de başı yoktu. Fakat Berlin müzesinde Babil eserleri arasındaki bir başın bu heykele ait olduğu keşfedilmiş ve böylece Puzur -İștar heykeli tamamlanmıștı (Resim : 1). Bu heykelin üzerindeki kitabede: "Puzur-İştar, Mari şakkanakku'su, biraderi rahip

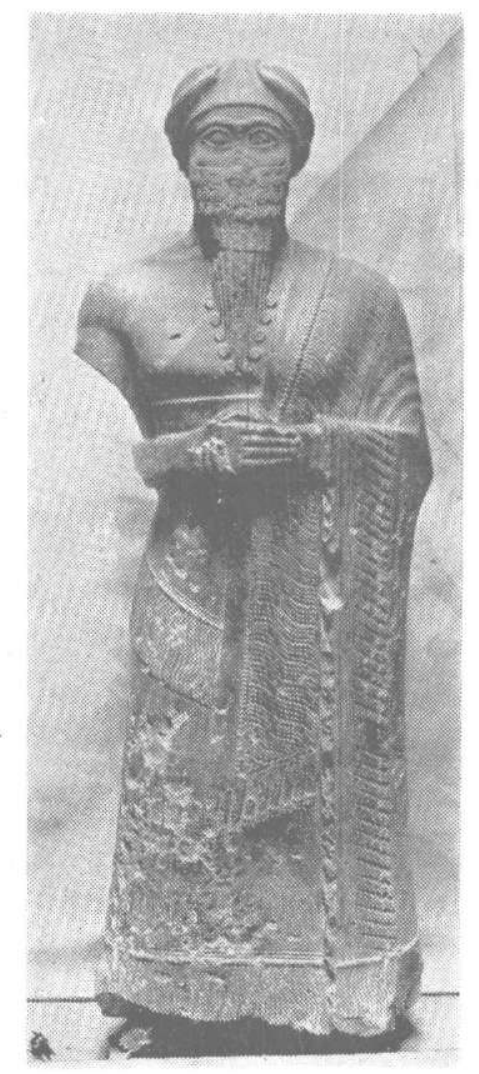

Resim : 1 Mari Şakkanakı Tura - Dağan oğlu Puzur - Iştar. (İstanbul Müzesinde).

Milga ile bunu adadılar" yazılıdır. Demek ki, Puzur-İştar bir defa babası ile, bir defa da rahip olan kardeşi ile birlikte mabede adak yapmıştı. 
Puzur-İştar heykelinde ilk dikkati çeken nokta, başın üzerinde bir tanri şapkası gibi, buğa boynuzlu bir türban bulunmasıdır. Herhalde bundan dolayıdır ki bu heykelleri ilk neşreden Esat Nasuhi, bunu bir Mari tanrısının heykeli zannetmişti. Yeni Mari kazılarının verdiği bilgilerle mesele artık aydınlanmış ve bu heykellerin Mari valilerine ait oldukları anlaşılmıştır.

Çünkü heykel ibadet vaziyetinde duran bir şahsı göstermektedir. Tanrı heykelleri ellerinde daima kudretlerinin sembollerini taşırlardı. Buna karşı Mezopotamya'da daha Er sülaleler devrinden beri böyle ellerini göğüs üzerinde kavuşturarak ibadet durumundaki heykelleri mabede koymak adetti. Bu suretle müminler daimi olarak tanrıların huzurunda dua ettikleri için tanrların onların dileklerini unutmayacaklarına inanıyorlardı. Bu geleneğe uyarak Mari valileri de ibadet durumunda yapılmış heykellerini mabede vakfetmişlerdi. Ancak bu taktirde Puzur-İştar'ın başındaki tanrılık alameti olan boynuzlar nasıl izah edilecekti?.

Bu sorulara cevap vermeden evvel, eserin tarihlenmesi gerekir. Bu hususta A. Parrot, 1937 senesinde Mari kazılarında sarayın bir şapelinde bulunan İdu-ilum heykeli (Resim: 2) ile kıyaslayarak, İstanbul müzesindeki Mari valilerinin heykellerini de III. Ur sülalesi zamanına koymuştu. Zira ona göre III. Ur sülalesi krallarından Gimil -Sin'in 7. senesine ait bir metinde zikredilen Tura-Dagan ile Mari valisi Tura-Dagan aynı şahıs idîler ${ }^{2}$. Bu netice, İdi-ilum ve Puzurİştar heykelleri kitabelerindeki yazı duktus'unun aynı olduğuna dayanarak Thureau-Dangin tarafından da tasdik edilmişti ${ }^{2}$ a. Aynı suretle Unger de İstanbul müzesindeki Mari heykellerini III. Ur Sülalesi zamaninda tarihliyordu ${ }^{3}$. Daha sonra G. Contenau bu heykelleri III. Ur sülalesini takibeden İsin-Larsa devrinin taşra üslubuna örnek sayıyordu ${ }^{4}$. A. Parrot en yeni eserinde Mari valilerine ait bütün heykelleri I. Babil devrine koymaktadır ${ }^{5}$.

Fakat Parrot'nun bu yeni tarihlemesi doğru görünmemektedir, çünkü, İstanbul arkeoloji müzesi çivi yazı koleksiyonundaki Puzuriş-

${ }^{2}$ A.Parrot, Syria XIX (1938) s. $183 . \quad{ }^{2}$ a RA 34 (1937) s. 172-176

' E. Unger, RIV VIII taf. V s.53 fig.52.

4 G.Contenau, Manuelle d'Archeologie Orientale II s. 798.

${ }^{5}$ A.Parrot, Archeologie Mesopotamièen I s. 498.(Paris 1946) ve Andrè Parrot, Sumer (1960) s. 270. 


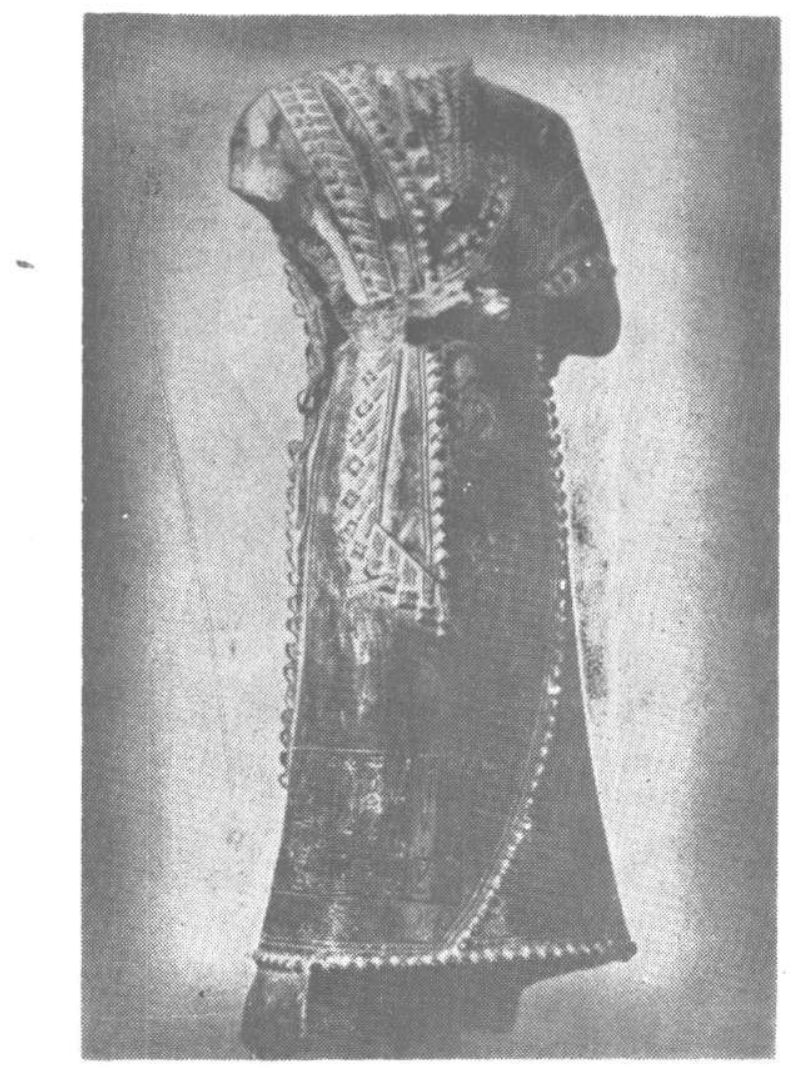

Resim : 2 Idi - flum, Mari Şakkanakı( Louure Müzesinde).

Dagan metinleri arasında Tura-Dagan ve Puzur-İştar adları geçmektedir ${ }^{6}$. Bunlardan Bur-Sin'in 5. senesine ait olan iki vesikada Tura-Dagan ve Puzur-Eştar zikredilmektedir. Gerçi vesikalarda bu şahısların Mari ile ilgili olduklarına dair bir kayıt yoktur, fakat buvesikalar Mari valilerine ait olmasa dahi, Mari valilerinin III. Ur sülalesinden başka bir devirde Mari'de yaşamış olmalarına imkân yoktur. Çünkü III. Ur sülalesinin çökmesinden sonraki Mezopotamya tarihi olaylarını hatırlarsak, müteakip İsin-Larsa devrinde Mari de

${ }^{6}$ M.Çı̆̆ - H.Kızılyay - A.Salonen, Istanbul Arkeoloji müzelerinde bulunan PuzurişDagan Metinleri (Helsinki 1954) No. $51=1$ bi-Sin'in 2. senesi; No: $122=$ Bur-Sin'in 5. senesi; No: 188 ve $372=$ Şulgi'nin 43. senesi; No: 141 Bur-Sin 5. senesi. 
istiklalini ilân etmiş ve hatta "Marili adam" denilen İşbi-İrra III. Ur kırallığının çöküşünde başlıca rolü oynamıştı. İsin-Larsa asrı sayılan M.Ö. 1950-1850 seneleri arasında ise Mari'de kıral İahdunLim ve oğlu İagit-Lim bulunuyordu. Bu devirde Mari kırallığı hakimiyetini Hana ve Terqa şehirlerine kadar yaymıştı. Fakat bu sırada I. Şamşi-Adad Asur'u ve Eşnunna (Tel Asmar) yı zaptetmek suretiyle en kuvvetli şehir devletlerinden biri haline gelmişti. Nitekim az sonra Mari'yi de zaptederek babasının intikamını almış ve buraya küçük oğlu Iasmah-Adad'ı kıral yapmıştı. Şamşi-Adad'ın ölümünden sonra oğlu iktidarı muhafaza edememiş ve Şamşi-Adad'ın Mari'de yaptığı katliamdan kurtularak Halebe kaçan Mari Prensi Zimri-Lim, muhtemelen Halep kıralının yardımı ile Asur prensi Iasmah-Adad'ı yenerek babasının tahtına oturmuştu.

Kıral Zimri-Lim'in Mari'deki saltanatı I. Babil sülalesinin en büyük kıralı meşhur Hammurabi'nin 33. senesine kadar devam edebilmiş ve Hammurabi bidayette dost olduğu Mari kırallı̆̆ı ile sonradan savaşarak Mari şehrini taş taş üzerinde kalmamasına tahrip ettirmişti. İstanbul müzesindeki Mari heykelleri muhtemelen ozamanlar harp ganimeti olarak Babil'e götürülmüştü. Mari kazıları şehrinin bundan sonra bir daha iskân edilmediğini göstermiştir. Mari valileri buna göre ancak III. Ur kıralları zamanında Ur'a tâbi olarak yaşamış olabilirler.

Heykellerin zamanını böylece tesbit ettikten sonra, şimdi yukarıda açık bıraktığımız soruya dönelim. Heykelin başındaki tanrı şapkası nasıl izah edilecektir. Kanaatimizce bu boynuzlu tasvir tarzı dahi heykellerin III. Ur sülalesi zamanına ait olduğuna bir delildir. Çünkü III. Ur sülalesi kıralları kendilerini" incarnation" suretiyle tanrılaştırıyorlardı. Vesikalarda bu devir kırallarının adları daima bir tanrı determinatifi ile yazllyordu. Mari valileri de herhalde aslen Mari prensleri ailesinden idiler. Zamanın anlayışına uyarak kendilerinin prens soyundan geldiklerini göstermek için başlarına bu tarzda bir türban giyiyorlardı. Hatta 7813 numaralı heykelin eteğindeki kitabede tanrılar arasında sayılan "Memleketin Beyi" ifadesi ile doğrudan doğruya Ur kıralı kastediliyordu. ?.

Bütün bunlardan başka heykellerin kıyafeti de bu tarihlemeyi doğrulamaktadır. Gerek bizim İstanbul müzesinde heykelleri bulunan Mari

7 R.Dussaud, Syria XIX (1939) s. 25 gŏre "Memleketin Beyi" tann Dagan'dur. 
valileri, gerekse İdu-ilum, Hindlilerin "sari"sini hatırlatan bir elbise giymiştirler. Takriben 4 metre uzunlukta bir tarafı saçaklı bütün bir kumaș parçasından ibaret olan bu elbise, bir ucundan evvela bir eteklik gibi bele bir defa sarılıyor, sonra öteki uç önden arkaya doğru dolanarak sol omuzdan aşağıya bir eşarp tarzında bırakılıyordu. Halen Louvre müzesinde bulunan Idi-İlum heykelindeki elbise biraz daha zengindir, onun elbise kumaşının bir tarafi püskül yerine küçük ponponlarla süslüdür, fakat serbest bırakılan eşarp kısmındaki saçaklar Puzur-İştar heykelindeki saçakların aymıdır. Aynı suretle her iki heykelin sakallarının yapılışı okadar birbirinin aymıdır ki, bu iki esere aynı ekolün, hatta belki de aynı sanatçının eseridir, denilebilir.

Bu kıyafeti biz III. Ur sülalesinin korucusu Ur-Nammu'nun Ur kazılarında bulunan steli üzerinde de görüyoruz. $\mathrm{Bu}$ günkü bilgilere göre örf ve adet hukukunu yazıya geçiren en eski Sumer kıralı olarak tanıdığımız Ur-Nammu, bu stelde aynı kıyafetle görünür. Yazık ki yalnız bir frizi tam olarak ele geçen bu kabartmada Ur kıralı aynı pozda bir defa Ur'un baş tanrısı Nannar'ın önünde, bir defa da Ay tanrısının zevcesi Nin-Gal'in önünde tasvir edilmiştir. Öyle ki kıralın elbisesi tanrıya doğru uzattığı sağ kolunun üzerini örttüğü halde, soldaki resimde tanriçaya uzatılan sağ kol çıplaktır, elbise burada sol kolun üzerinden atılmıştır. III. Ur sülalesi zamanına ait silindir mühürler üzerinde de bu kıyafete daima rastlanır.

İstanbul arkeoloji müzesindeki üçüncü bir Mari eseri de üzerinde kabartma ve kitabe bulunan bir stel parçasıdır.

Bu stelin Babil kazlarında bulunması, M.Ö. 612 de vukubulan Asur imparatorluğunun çökmesi sırasındaki yağmada Babil valisi NabuPolassar tarafindan Babil'e getirilmesile izah edilmiştir. Asur devrine ait olan bu Mari kabartması İstanbul müzesinde 7815 numarada kayıth olup, bir tapınma sahnesini tasvir etmektedir (Resim: 3). Üzerindeki kitabede kendisine "Mari ve Sukhi memleketlerinin şakkanakı" diyen Şamaş-reş-usur memleketine hurma ağaçlan diktiğini, oraya ilk defa bal arılarını kendisinin getirdiğini söylemektedir ${ }^{8}$.

$\mathrm{Bu}$ eser, kıyafetlerin modasına göre çok daha geçtir, takriben IX.-X. yüzyıllar arasına konulmaktadır. Kabartmada tam orta yerde duran ve diğer figürlere nazaran daha küçük nisbette tasvir edil-

${ }^{8}$ Gressmann, Altorientalische Texte und Bilder zum Altentestament (Leipzig 1927) No: 330 s. 94. 
miş olan şahıs bizzat Şamaş-reş-usur'dur. Onun tam karşısında dağları sembolize eden bir kaide üzerinde, ellerindeki şimşek demetleri ile Frrtına tanrısı Adad durmaktadır. Onun arkasında ise sol eli üzerindeki yıldız işaretinden İştar olduğunu anladığımız aşk ve harp tanrıçası durmaktadır. Şamaş-reş-usur'un arkasındaki tanrının yukarı bedeni kırılmıştır, fakat başı üzerindeki Hilâl resminden onun da Ay tanrısı Sin olduğu tahmin edilebilir.

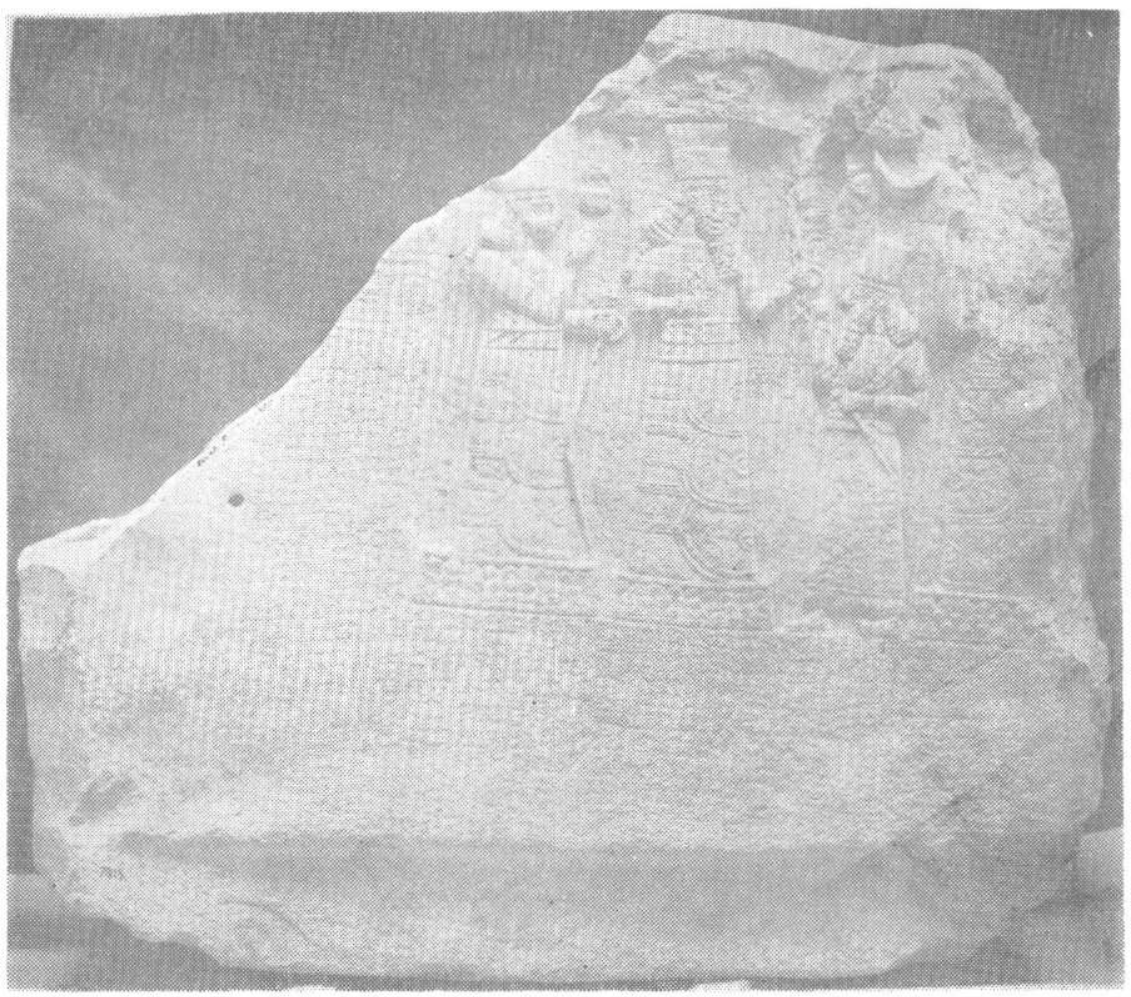

Resim : 3 šamaš - seš. Uşar.

Şamaş-reş-usur'un elbisesi tamamen yeni Asur devri modasını göstermektedir. Ayaklarındaki sandallar da bunu tasdik etmektedir. Sol elinde bir topuz tutmakta, sağ elini ise tanrıları selamlar durumda yukarı kaldırmaktadır. 
Tannların kıyafetleri tabii daha eski bir modayı göstermektedir. Tanrıça Iştar'in sağ eli üzerinde ise Yazı tanrısı Nabu'nun sembolü kalem ile Amurit tanrısı Marduk'un bir kaide üzerinde duran ok ucu görülmektedir.

Bu eserin sanat bakımından değeri tanrıça İştar'ın ananevi ikonokrafisinin aksine elbisesinin bacaklarını tamamen örtmesi ve Mari valisi gibi tam profilden yapılmış olmasıdır. Buna karşı tanrı Adad'ın tasvirinde eski ananeye sadık kalınmış, yani baş ve ayaklar profilden olduğu halde, yukarı beden cepheden yapılmak sureti ile profil ve "en face" tasvir tarzı aynı figür üzerinde birleştirilmiştir. 